\title{
Folic acid and neural tube defects
}

\author{
Helga V. Toriello, PhD, for the Professional Practice and Guidelines Committee
}

Key Words: folic acid supplementation, neural tube defects, prenatal diet, congenital anomalies

Major congenital anomalies occur in 2\% to 3\% of live births. Neural tube defects (NTDs), cleft lip and palate, and cardiac anomalies are some of the most common. NTDs are a group of serious birth defects that affect the developing nervous system and include anencephaly, spina bifida, and encephalocele. Birth records suggest that about 2500 babies with these birth defects, or 1 to 2 per 1000, are born each year in the United States. Some affected pregnancies are spontaneously or electively aborted. Over $95 \%$ occur to women without a prior family history of this disorder. Neural tube defects occur within 1 month of conception. Anencephaly and spina bifida are the most common NTDs and occur with about equal frequency, whereas encephalocele is seen less frequently. In anencephaly, there is partial or complete absence of the skull bones usually with a remnant of brain: it is almost always fatal before or shortly after birth. Spina bifida with meningomyelocele results from failure of the vertebral arches to close over an open neural tube defect, exposing the spinal cord and nerves. Although most cases of spina bifida are open, $10 \%$ to $15 \%$ are closed or covered by skin. Spina bifida is compatible with survival although in most cases individuals have moderate to severe disabilities and, in some cases, may have mental retardation. With encephalocele there is protrusion of the brain and/or its covering membranes through the skull, most often in the occipital region.

Folic acid supplementation has been shown to reduce the incidence and recurrence of NTDs and possibly reduce the occurrence of several other birth defects such as cardiac, orofacial, limb, and renal anomalies (see References ${ }^{1,2}$ ). For women without a prior history of NTDs, 4 of 5 studies reported decreases of $40 \%$ to $100 \%$ if folic acid was taken on a daily basis. ${ }^{3-8}$ For women with a prior history of NTDs, all published studies reported a similar reduction after folic acid supplementation. ${ }^{9-12}$ The dose of folic acid, either alone or part of a multivitamin preparation, varied between 400 to $5000 \mu \mathrm{g}(0.4-5$ $\mathrm{mg}$ ) per day and was taken at least 1 month before conception and throughout the first trimester. Because neural tube closure occurs within the first 28 days after conception, which is often before the recognition of pregnancy, and because many preg-

\footnotetext{
Helga V. Toriello, PhD, Spectrum Health, Grand Rapids, Michigan.

American College of Medical Genetics, 9650 Rockville Pike, Bethesda, MD 20914-3998.

Approved by the ACMG Board of Directors October 26, 2004.

This statement supersedes the statements entitled "Folic Acid and Pregnancy" (1994) and

"Folic Acid: Statement on Fortification and Supplementation" (1997).

Go to www.geneticsinmedicine.org for a printable copy of this document.

See disclaimer at the end of this article
}

nancies are unplanned, NTD prevention is best achieved by adequate daily folic acid intake throughout the reproductive years.

Women without a prior history of a NTD should ingest 400 $\mu \mathrm{g}(0.4 \mathrm{mg})$ of folic acid each day throughout their reproductive years, either as a supplement, in a multivitamin, from foods fortified with folic acid, or a combination of these. ${ }^{13}$ Available reports suggest that $400 \mu \mathrm{g}(0.4 \mathrm{mg})$ is sufficient to cause a substantial reduction of NTDs (40\%-80\%, dependent on background NTD prevalence). ${ }^{8}$ While it is possible for women to increase their consumption of dietary folates by careful selection of foods, food folates are about half as bioavailable as synthetic folic acid. Fortification of staple food products with synthetic folic acid is an effective and inexpensive approach to increasing overall folic acid intake without the need for behavior change. Women are continuing to eat the foods they have always eaten (unless they choose to follow certain low carbohydrate diets), but are now receiving the benefits of folic acid that has been added to these foods. In 1998, the Food and Drug Administration mandated the fortification of enriched cereal grain flours with $140 \mu \mathrm{g}$ synthetic folic acid per 100 grams of grain. Studies show that after fortification, prevalence of spina bifida decreased by $31 \%$, and prevalence of anencephaly decreased by $16 \% .{ }^{14}$ Although this is a step forward, the actual amount added may not be sufficient to protect against all folic acid-preventable NTDs. For women who have had a prior pregnancy with a NTD, following the report of the British MRC Vitamin Study, ${ }^{10}$ the Centers for Disease Control recommended supplementation with $4 \mathrm{mg}$ of folate daily beginning at least one month before conception. ${ }^{15}$

Although Vitamin B12 deficiency is rare in women and children, there is concern that folic acid dosages exceeding $1000 \mu \mathrm{g}$ $(1.0 \mathrm{mg})$ per day may hinder the diagnosis of this condition, thereby allowing any neurological symptoms to progress to irreversible deficits. For most women, the recommended amounts of folic acid obtained from folic acid supplements and food fortification are unlikely to exceed the $1000 \mu \mathrm{g}$ per day. Cumulative effects are unlikely since folic acid is highly water soluble and is rapidly excreted.

Because the American College of Medical Genetics (ACMG) is committed to the prevention of congenital anomalies, we support the following recommendations:

(1) Women capable of becoming pregnant should take 400 $\mu \mathrm{g}(0.4 \mathrm{mg})$ of folic acid daily, in the form of a supplement, multivitamin, and/or through fortified foods, in addition to eating a healthy diet. This is particularly 
important before conception and through the first trimester of pregnancy.

(2) Women who have had a prior NTD-affected pregnancy, who have a first-degree relative with a NTD, or who are themselves affected should consult with their physicians before becoming pregnant. They should obtain genetic counseling concerning their occurrence or recurrence risks, pregnancy management, and the appropriate folic acid intake for them. They may be advised to take 4000 $\mu \mathrm{g}(4.0 \mathrm{mg})$ of folic acid daily starting at least 1 month and preferably 3 months before conception.

(3) Because of a potential concern of masking timely detection of B12 deficiency, the total daily intake of folic acid should not exceed $1000 \mu \mathrm{g}(1.0 \mathrm{mg})$ unless prescribed by a physician. Recent evidence, however, indicates that fortification has not led to a major increase in masking of vitamin B12 deficiency. ${ }^{16}$

\section{REFERENCES}

1. Hall JG, Solehdin F. Folate and its various ramifications. Adv Pediatr 1998;45:1-35.

2. McDonald SD, Ferguson S, Tam L, Lougheed J, Walker MC. The prevention of congenital anomalies with periconceptional folic acid supplementation. J Obstet Gynaecol Can 2003;25:115-121.

3. Mulinare J, Cordero JF, Erickson JD, Berry RT. Periconceptional use of multivitamins and the occurrence of NTDs. JAMA 1988;260:3141-3145.

4. Bower C, Stanley FJ. Dietary folate as a risk factor for NTDs: Evidence from a case control study in Western Australia. Med J Aus 1989;150:613-619.

5. Mills JL, Rhoads GG, Simpson JL, Cunningham GC, Conley MR, Lassman MR et al. The absence of a relationship between the periconceptional use of vitamins and NTDs. N Engl J Med 1989;321:430-435.
6. Milunsky A, Jick H, Jick SS, Bruell CL, MacLaughlin DS, Rothman KJ, Willett W. Multivitamin/folic acid supplementation in early pregnancy reduces the prevalence of neural tube defects. JAMA 1989;262:2847-2852.

7. Czeizel A, Dudas I. Prevention of first occurrence of neural tube defects by periconceptional vitamin supplementation. N Engl J Med 1992;327:1831-1835.

8. Berry RJ, Li Z, Erickson JD, Li S, Moore CA, Wang H et al. Prevention of neural-tube defects with folic acid in China: China-U.S. Collaborative Project for Neural Tube Defect Prevention. N Engl J Med 1999;341:1485-1490.

9. Laurence KM, James N, Miller MH, Tennant GB, Campbell H. Double-blind randomized controlled trial of folate treatment before conception to prevent recurrence of neural-tube defects. Br Med J 1981;282:1509-1511.

10. Medical Research Council Vitamin Study Research Group. Prevention of neural tube defects: results of the Medical Research Council Vitamin Study. Lancet 1991; 338: 131-137.

11. Smithells RW, Nevin NC, Seller MJ, Sheppard S, Harris R, Read AP et al. Further experience of vitamin supplementation for prevention of neural tube defect recurrences. Lancet 1983;1:1027-1031.

12. Vergel RG, Sanchez LR, Heredero BL, Rodriguez PL, Martinez AJ. Primary prevention of neural tube defects with folic acid supplementation: Cuban experience. Prenat Diagn 1990;10:149-152.

13. Workshop on folate, B12, and choline. Sponsored by the Panel on Folate and other $B$ vitamins of the Standing Committee on the Scientific Evaluation of Dietary Reference Intakes, Food and Nutrition Board, Institute of Medicine, Washington, D.C., March 3-4, 1997. Nutrition 1999;15:92-96.

14. Williams LJ, Mai CT, Edmonds LD, Shaw GM, Kirby RS, Hobbs CA et al. Prevalence of spina bifida and anencephaly during the transition of mandatory folic acid fortification in the United States. Teratology 2002;66:33-39.

15. Birth Defects and Genetic Diseases Branch, Division of Birth Defects and Developmental Disabilities, National Center for Environmental Health and Injury Control, CDC. Use of folic acid for prevention of spina bifida and other neural tube defects: 1983-1991. Morb Mortal Wkly Rep 1991;40:513-516.

16. Mills JL, Von Kohorn I, Conley MR, Zeller JA, Cox C, Williamson RE et al. Low vitamin B-12 concentrations in patients without anemia: the effect of folic acid fortification of grain. Am J Clin Nutr 2003;77:1474-1477.

Disclaimer: This statement is designed primarily as an educational resource for medical geneticists and other health care providers to help them provide quality medical genetic services. Adherence to this statement does not necessarily ensure a successful medical outcome. This statement should not be considered inclusive of all proper procedures and tests or exclusive of other procedures and tests that are reasonably directed to obtaining the same results. In determining the propriety of any specific procedure or test, the geneticist should apply his or her own professional judgment to the specific clinical circumstances presented by the individual patient or specimen. It may be prudent, however, to document in the patient's record the rationale for any significant deviation from this statement. 